\title{
Molecular Parameters and Intrinsic Viscosity of Nettle Seed (Urtica Pilulifera) Gum as a Function of Temperature
}

\section{Zahra Zamani}

Ferdowsi University of Mashhad

Seyed Mohammad Ali Razavi ( $\sim$ s.razavi@um.ac.ir)

Ferdowsi University of Mashhad

\section{Research Article}

Keywords: Nettle seed gum (NSG), hydrocolloids, Higiro 2 model, intrinsic viscosity

Posted Date: January 22nd, 2021

DOI: https://doi.org/10.21203/rs.3.rs-151482/v1

License: (c) (1) This work is licensed under a Creative Commons Attribution 4.0 International License.

Read Full License 
1 Molecular parameters and intrinsic viscosity of Nettle seed (Urtica pilulifera)

gum as a function of temperature

Zahra Zamani $^{1}$, Seyed M.A. Razavi ${ }^{*}$

5

6 This research focused to determine some molecular properties of Nettle seed gum (NSG), as one of 7 novel and natural source of hydrocolloids, at various temperatures $\left(10,25,40,55\right.$, and $\left.70^{\circ} \mathrm{C}\right)$ in the

8 dilute region. The results displayed that among the models studied, the Higiro 2 model with highest

$9 \quad \mathbf{R}^{2}$ and lowest RMSE values was the most proper model for determining the intrinsic viscosity of the NSG. According to this model, the intrinsic viscosity value of NSG was obtained in the range of 0.15-0.21 dl/g. It was also revealed that, as the temperature raised, the intrinsic viscosity of NSG declined. The shape factor of NSG at $40^{\circ} \mathrm{C}$ was spherical, however, with increasing the temperature from $40^{\circ} \mathrm{C}$ to $70^{\circ} \mathrm{C}$, it was changed to an ellipsoidal shape. Berry number and master curve slope revealed that NSG solution at all temperatures was within the dilute regime and that no molecular entanglements were present. The parameter $b$ values acquired for NSG at the intended temperatures showed that the molecular conformation of NSG was random coil. The activation energy and chain flexibility parameter calculated for NSG at the studied temperatures were $0.488 \times 10^{7} \mathrm{~J} / \mathrm{kgmol}$ and 587.2 , respectively.

\footnotetext{
${ }^{1}$ Department of Food Science and Technology, Ferdowsi University of Mashhad, PO Box: 91775-1163, Mashhad, Iran. *Corresponding author email: s.razavi@um.ac.ir
} 
21 Urtica pilulifera L. is a member of the Urticaceae family ${ }^{1}$. Urtica pilulifera L. plant grows

22 widely in areas with the Mediterranean climate ${ }^{2}$. This plant has been applied for the treatment of

23 gastritis, urinary infections, and enteritis, rheumatism, liver inflammation, also skin diseases ${ }^{3}$.

24 When Urtica pilulifera seeds are placed in water, the mucilaginous layer around the seeds absorb water and swell. Recently, the optimal conditions for extraction of Nettle seed (Urtica pilulifera) mucilage (NSG) were identified by the response surface methodology (RSM) ${ }^{4}$. Also, some

27 physicochemical, rheological, and functional properties of NSG as a novel and natural source of 28 hydrocolloids has been recently perused ${ }^{5}$. The chemical compositions of NSG were reported as 29 follows: moisture, 9.50\%; ash, 15.30\%; protein, 10.42\%; lipids, 1.02\%; carbohydrate, $63.09 \%$ and uronic acids, $10.75 \%$, indicating the polyelectrolyte nature of this hydrocolloid. The 31 constituent sugars of NSG were composed of rhamnose (13.98\%), arabinose (0.02\%), galactose $32(2.99 \%)$, glucose $(2.61 \%)$, xylose $(0.07 \%)$, and galacturonic acid $(24.71 \%)$. Besides, the effects 33 of shear rate $\left(14-400 \mathrm{~s}^{-1}\right)$, concentration $(3-5 \%)$, and temperature $\left(10-70^{\circ} \mathrm{C}\right)$ on the rheological 34 properties of NSG were studied and modelled. It was also revealed that the NSG can be used as 35 an emulsion/foam stabilizer in the food and pharmaceutical systems ${ }^{5}$.

36 Viscosity estimation in the dilute solution regime, in which individual polysaccharide coils are 37 well separated from each other, and are free to move independently, is crucial in providing the 38 information on how molecules behave in solution and the way the structure and fundamental 39 properties of biopolymers are related $^{6}$. The intrinsic viscosity, $[\eta]$, is a characteristic of macromolecules that directly depends on their ability to disturb the flow and indirectly on the 41 size and shape of the molecules ${ }^{7}$. Attractive and repulsion interactions between macromolecules 42 chains affect the hydration and as a result, the hydrodynamic volume of the molecules, the 43 hydrodynamic volume is mainly related to the conformation of macromolecules in solution. The 
44 changes in the molecular parameters such as hydrodynamic volume, conformation, shape, and 45 macromolecular entanglements can be witnessed by variations in the intrinsic viscosity ${ }^{8}$. Many 46 researches have been done to determine the intrinsic viscosity of different hydrocolloids ${ }^{9-16}$. The 47 molecular parameters including solution viscosities, molecular shape \& conformation, 48 voluminosity, and etc. seem to be beneficial to understand and predict the functional properties 49 of hydrocolloids in the semi-dilute solution regime at various conditions like temperature, $\mathrm{pH}$, 50 and etc. Due to the diversity in biopolymers' structure and also external conditions in the fluid

51 flow systems, the dilute solution properties are greatly dependent to the selected biopolymer ${ }^{15}$.

52 The literature review displays the absence of perfect and enough data concerning this emerging 53 hydrocolloid in the dilute solution domain. Therefore, this research aimed at the effect of 54 temperature (at the levels of $10,25,40,55$, and $70{ }^{\circ} \mathrm{C}$ ) on some dilute solution properties 55 (intrinsic viscosity; voluminosity, and shape factor; molecular conformation; activation energy 56 and chain flexibility parameter) of the NSG to evaluate its potentials in the food and 57 pharmaceutical systems.

\section{Materials and methods}

60 Sample preparation. Nettle seed (Urtica pilulifera) gum was produced under the optimized 61 conditions, as expressed by Zamani et al. ${ }^{4}$. Nettle seeds were soaked in the distilled water at a 62 water/seed ratio of $40: 1$ and a set temperature of $59 \pm 1.0{ }^{\circ} \mathrm{C}$ for a period of $3.4 \mathrm{~h}(204 \mathrm{~min})$. Then, 63 the mucilage was extracted from the swelled seeds by a lab-scale extractor (model 402, Pars64 Khazar Com., Iran) and dried in a forced-convention laboratory oven (model 4567, Kimya Pars 65 Com., Iran) at $36{ }^{\circ} \mathrm{C}$, milled and sieved by applying a mesh 18 sifter. NSG powders were 66 packaged in seal bags and maintained in a cool and dry place for further measurements. 
Estimation of intrinsic viscosity. Gum solutions $(2.5 \mathrm{~g} / \mathrm{dl})$ were prepared by dispersing the NSG powder in deionized water. The samples were then stirred $(500 \mathrm{rpm})$ with a magnetic stirrer for

$7060 \mathrm{~min}$ at $25 \circ \mathrm{C}$ until complete dissolution, and the solutions were placed in a refrigerator at $4 \circ \mathrm{C}$

71 for $24 \mathrm{~h}$ to complete the hydration. The dynamic viscosity of the NSG solutions $(\eta)$ and the

72 solvent $\left(\eta_{\mathrm{s}}\right.$, deionized water) were measured at three replications in a thermostatic water bath,

73 using an Ubbelohde capillary viscometer (Cannon Instrument, USA; capillary tube No. 100,

$74 \mathrm{~K}=0.019908 \mathrm{~mm}^{2} / \mathrm{s}^{2}$ ). The measurements were performed at five temperature levels of 10,25 , 7540,55 , and $70^{\circ} \mathrm{C}$. To obtain the dynamic viscosity of the samples, the time of passage between 76 two lines marker of the viscometer was recorded. Data were used to calculate the relative 77 viscosity $\left(\eta_{\text {rel }}\right)$ and specific viscosity $\left(\eta_{\mathrm{sp}}\right)$ using the following relationships:

78

79

80

81

82

83

8

9

$$
\eta_{\text {rel }}=\eta / \eta_{s}
$$

$$
\eta_{s p}=\eta-\frac{\eta_{s}}{\eta_{s}}=\eta_{r e l}-1
$$

$$
\text { The intrinsic viscosity [ } \eta] \text { is often estimated using the Huggins equation (3) and Kraemer }
$$
equation (4) models. Based on these models, the reduced viscosity $\left(\eta_{s p} / C\right)$ and inherent viscosity $\left(\ln \eta_{r e} / C\right)$ data versus the gum concentration were plotted and then the curves were extrapolated to zero concentration. The intercepts were considered as the intrinsic viscosity ${ }^{17}$.

\section{Huggins' equation ${ }^{18}$ :}

$$
\frac{\eta_{s p}}{C}=[\eta]+K_{H}[\eta]^{2} C
$$


Kraemer's equation ${ }^{19}$ :

$$
\frac{\ln \eta_{r e l}}{C}=[\eta]+K_{K}[\eta]^{2} C
$$

where, $k_{H}, k_{k}$, and $C$ are the Huggins constant, the Kraemer constant; and the gum concentration, respectively. McMillan et al. ${ }^{20}$ stated that methods of intrinsic viscosity determination based on slopes of plots (e.g. Tanglertpaibul-Rao's model equation (5) and Higiro's models equations (6), and (7) have a higher correlation coefficient and a lower standard error than the methods based on the extrapolation (e.g. Huggins and Kraemer models). Nickerson et al. ${ }^{21}$ also stated that since polymer concentrations are provided by sequential dilution, the error in the expression $\left(\eta_{\mathrm{sp}} / \mathrm{C}\right)$ increases, and the data fitting to the Huggins model is difficult. Therefore, in the present study, three following slope-based models were used to estimate the intrinsic viscosity of the samples. Tanglertpaibul-Rao's equation ${ }^{7}$ :

$$
\eta_{\text {rel }}=1+[\eta] C
$$

Higiro's equations ${ }^{22}$ :

$$
\eta_{\text {rel }}=e^{[\eta] C}
$$

Estimation of Shape factor and swollen volume parameters. Based on the following equation, intrinsic viscosity depends on two crucial molecular parameters, namely the shape factor and swollen volume $e^{23}$ : 
116 where, $v$ is the biopolymer shape factor which is known as the viscosity increment, and $v_{s}$ is the

117 biopolymer swollen volume or the voluminosity. The swollen volume depends on relative 118 viscosity and is determined from the intercept of the plot of $\mathrm{Y}$ versus the concentration as 119 follows:

$$
Y=\eta_{r e l^{0.5}}-1 /\left[C\left(1.35 \eta_{r e l^{0.5}}-0.1\right)\right]
$$

123 Estimation of molecular conformation. The power-law relationship equation (10) was applied to 124 determine the exponent $b$, as the slope of the logarithmic diagram of the specific viscosity versus 125 the concentration. This parameter is generally used to describe the polysaccharide 126 conformation $^{24}$.

127

128 129

$$
[\eta]=A e^{E_{a} / R T}
$$


136 where, $[\eta]$ is the intrinsic viscosity $(\mathrm{dl} / \mathrm{g}), A$ is the model constant, $E_{a}$ is the activation energy

$137(\mathrm{~kJ} / \mathrm{kgmol}), R$ is the universal gas constant $(\mathrm{kJ} / \mathrm{kgmol} . \mathrm{K})$, and $T$ is the absolute temperature $(\mathrm{K})$.

138 Typically, the $E_{a} / R$ value is an indicator of biopolymer's chain flexibility so that high values of $139 E_{a} / R$ indicate low chain flexibility ${ }^{25}$.

141 Statistical analysis. To survey the effect of temperature (at five levels of $10,25,40,55$, and $70^{\circ} \mathrm{C}$ )

142 on the dilute solution properties of NSG, a completely randomized design with three repetitions, 143 and Duncan test at a 95\% confidence level were applied for statistical analysis and comparing 144 means by SPSS software version 22, respectively. Also, MATLAB software (R2013a) was used 145 to select the most appropriate model for intrinsic viscosity estimation. Microsoft Excel 2010 146 software was used to draw the graphs.

\section{$148 \quad$ Results and discussion}

149 Intrinsic viscosity. Intrinsic viscosity is an indicative of the hydrodynamic volume occupied by 150 each macromolecule ${ }^{26}$, which provides an in-depth insight into the molecular characteristics ${ }^{10}$. 151 The interaction between various polymers, the fragments of a polymer chain, and between the 152 polymer chains and the solvent molecules affects the polymer conformation. On the other hand, 153 polymer conformation is affected by temperature and polymer concentration ${ }^{27}$. In this study, the 154 intrinsic viscosity was specified by two methods, that in the first method, it was estimated using 155 the Huggins and Kraemer equations (3), and (4), while in the second method, it was computed by 156 the Tanglertpaibul \& Rao equation (5) and Higiro $1 \& 2$ equations (6), and (7) ${ }^{11,20}$. Figures 1 and 1572 show the results of fitting by the investigated models to the experimental data obtained for 158 NSG in the dilute regime. In the present research, due to the lack of a logical relationship 
159 between intrinsic viscosity and temperature changes, Huggins and Kramer's equations were not 160 considered as the appropriate models (Table 1). Slope-based relations (Tanglertpaibul-Rao, 161 Higiro 1 \& Higiro 2) showed high efficiency for determination of the intrinsic viscosity of NSG 162 at $25{ }^{\circ} \mathrm{C}$, because they displayed a better linear fit with maximum $\mathrm{R}^{2}$ and minimum RMSE 163 values (Table 2). McMillan ${ }^{20}$, and Razavi et al. ${ }^{11}$, also found that slope-based methods had 164 higher significant correlation coefficients and lower standard errors than those intercept-based 165 166 167 168 169 170 171 172 polysaccharides (such as xanthan), due to the electrostatic repulsion between the chains and the 173 dimensions of the developed helix, reduced viscosity $\left(\eta_{\mathrm{sp}} / \mathrm{C}\right)$ increases steadily with very rapidly 174 slope with increasing polymer concentration. According to Figure 1, the behavior of NSG is 175 similar to that described for ionic polysaccharides by Lapasin and Prickel ${ }^{30}$. As shown in Table 176 2, about the effect of temperature, the Higiro 2 model (equation (7)) displayed highest efficiency 177 among the applied models because of the higher $\mathrm{R}^{2}$ and lower RMSE values obtained. Therefore, 178 this model was selected as the most appropriate model for computing the intrinsic viscosity of 179 the NSG. Based on this model, the intrinsic viscosity value of NSG has obtained as $0.2 \mathrm{dl} / \mathrm{gr}$ at $18025^{\circ} \mathrm{C}$. When the temperature enhanced from $10^{\circ} \mathrm{C}$ to $70^{\circ} \mathrm{C}$, the intrinsic viscosity of NSG 181 decreased from 0.2 to $0.15 \mathrm{dl} / \mathrm{gr}$ (Table 2). Because of increasing the vibrations of molecules and 
182 intermolecular distance, it may be attributed to the abruption change in the gyration of NSG 183 macromolecules as a result of increasing their chains' flexibility ${ }^{28,31}$. These results were 184 consistent with previous observations ${ }^{10,12,13,32,33}$. Oppositely, Stivala and Bahary ${ }^{34}$ expressed that 185 by raising temperature from 25 to $57{ }^{\circ} \mathrm{C}$, the intrinsic viscosity of Levan was increased. 186 Furthermore, Haug and Smidsrod $^{35}$ stated that the temperature has little effect on intrinsic 187 viscosity of alginate. In comparison, the intrinsic viscosity of NSG was almost the same as 188 reported for Anghouzeh gum $(0.213 \mathrm{dl} / \mathrm{gr})^{36}$, and Albizia gum $(0.23 \mathrm{dl} / \mathrm{gr})^{37}$, and lower than guar $189(9.25 \mathrm{dl} / \mathrm{gr})^{38}$, xanthan gum $(214.21 \mathrm{dl} / \mathrm{gr})^{22}$, and Nettle seed (Urtica dioica) gum $(8.56 \mathrm{dl} / \mathrm{gr})^{16}$, 190 and higher than cashew gum $\left(0.1 \mathrm{dl} / \mathrm{gr} \text { at } 20^{\circ} \mathrm{C}\right)^{39}$, and gum Arabic $\left(0.177 \mathrm{dl} / \mathrm{gr} \text { at } 25^{\circ} \mathrm{C}\right)^{40}$. 191

\begin{tabular}{lllllll}
\hline & \multicolumn{1}{l}{ Huggins } & \multicolumn{5}{l}{ Kraemer } \\
\cline { 2 - 7 } Temperature & {$[\eta]$} & $\mathrm{R}^{2}$ & RMSE & {$[\eta]$} & $\mathrm{R}^{2}$ & RMSE \\
$\left({ }^{\circ} \mathrm{C}\right)$ & & & & & & \\
\hline 10 & $0.100 \pm 0.042^{\mathrm{b}}$ & 0.844 & 0.037 & $0.168 \pm 0.033^{\mathrm{b}}$ & 0.689 & 0.052 \\
25 & $0.179 \pm 0.004^{\mathrm{a}}$ & 0.974 & 0.007 & $0.217 \pm 0.003^{\mathrm{a}}$ & 0.920 & 0.004 \\
40 & $0.138 \pm 0.003^{\mathrm{ab}}$ & 0.975 & 0.005 & $0.181 \pm 0.001^{\mathrm{b}}$ & 0.868 & 0.005 \\
55 & $-0.395 \pm 0.011^{\mathrm{d}}$ & 0.872 & 0.017 & $-0.249 \pm 0.006^{\mathrm{d}}$ & 0.781 & 0.013 \\
70 & $-0.041 \pm 0.016^{\mathrm{c}}$ & 0.970 & 0.006 & $0.027 \pm 0.010^{\mathrm{c}}$ & 0.943 & 0.005 \\
\hline
\end{tabular}

192

Table 1. Comparison of intrinsic viscosity ([ๆ], dl/gr) of Nettle seed gum (NSG) solution using 194 Huggins and Kraemer models at different temperatures. Results are expressed as means \pm SD for 195 three replications. a-d: Means followed by the same letters in the same column for each 196 temperature are not significantly different $(\mathrm{P}>0.05)$. 


\begin{tabular}{|c|c|c|c|c|c|c|c|c|c|}
\hline \multirow{2}{*}{$\begin{array}{l}\text { Temperature } \\
\left({ }^{\circ} \mathrm{C}\right)\end{array}$} & \multicolumn{3}{|l|}{ Higiro (1) } & \multicolumn{3}{|l|}{ Higiro (2) } & \multicolumn{3}{|c|}{ Tanglertpaibul \& Rao } \\
\hline & {$[\eta]$} & $\mathrm{R}^{2}$ & RMSE & {$[\eta]$} & $\mathrm{R}^{2}$ & RMSE & {$[\eta]$} & $\mathrm{R}^{2}$ & RMSE \\
\hline 10 & $0.269 \pm 0.001^{\mathrm{a}}$ & 0.947 & 0.057 & $0.208 \pm 0.001^{\mathrm{a}}$ & 0.986 & "0.031 & $0.360 \pm 0.001^{\mathrm{a}}$ & 0.849 & 0.114 \\
\hline 25 & $0.268 \pm 0.001^{\mathrm{a}}$ & 0.977 & 0.023 & $0.208 \pm 0.001^{\mathrm{a}}$ & 0.991 & 0.009 & $0.356 \pm 0.002^{\mathrm{a}}$ & 0.899 & 0.081 \\
\hline 40 & $0.245 \pm 0.001^{\mathrm{a}}$ & 0.959 & 0.023 & $0.195 \pm 0.001^{\mathrm{a}}$ & 0.991 & 0.007 & $0.315 \pm 0.002^{\mathrm{ab}}$ & 0.868 & 0.066 \\
\hline 55 & $0.189 \pm 0.001^{b}$ & 0.813 & 0.180 & $0.157 \pm 0.001^{b}$ & 0.896 & 0.133 & $0.233 \pm 0.002^{b c}$ & 0.718 & 0.248 \\
\hline 70 & $0.181 \pm 0.001^{\mathrm{b}}$ & 0.792 & 0.042 & $0.150 \pm 0.000^{\mathrm{b}}$ & 0.875 & 0.022 & $0.222 \pm 0.001^{\mathrm{c}}$ & 0.706 & 0.072 \\
\hline
\end{tabular}

197

198 Table 2. Comparison of intrinsic viscosity ([ๆ], dl/gr) of Nettle seed gum (NSG) solution using Tanglertpaibul \& Rao and Higiro models at different temperatures. Results are expressed as means \pm SD for three replications. a-c: Means followed by the same letters

200 in the same column for each temperature are not significantly different $(\mathrm{P}>0.05)$. 


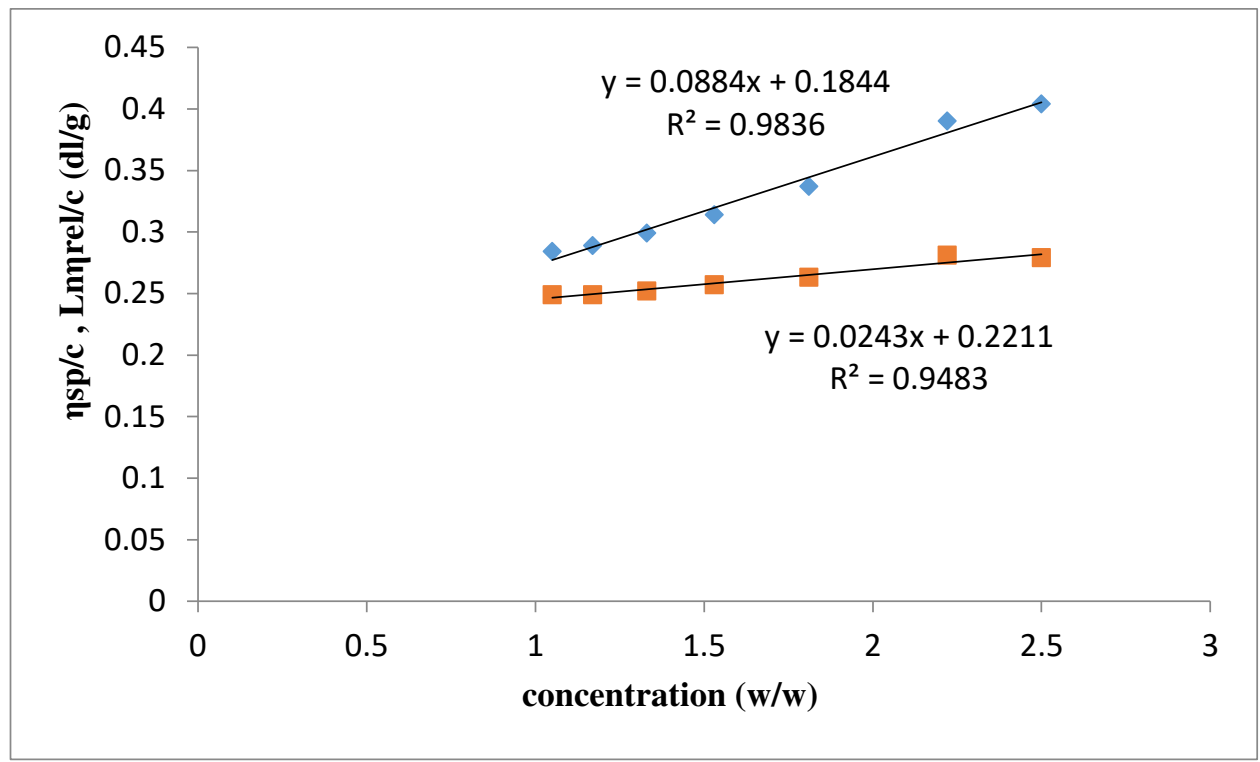

203 Figure 1. A typical dual Huggins ( $\diamond$ ) and Kraemer (๘) plots of Nettle seed gum (NSG) in 204 deionized water $\left(25^{\circ} \mathrm{C}\right)$.

205

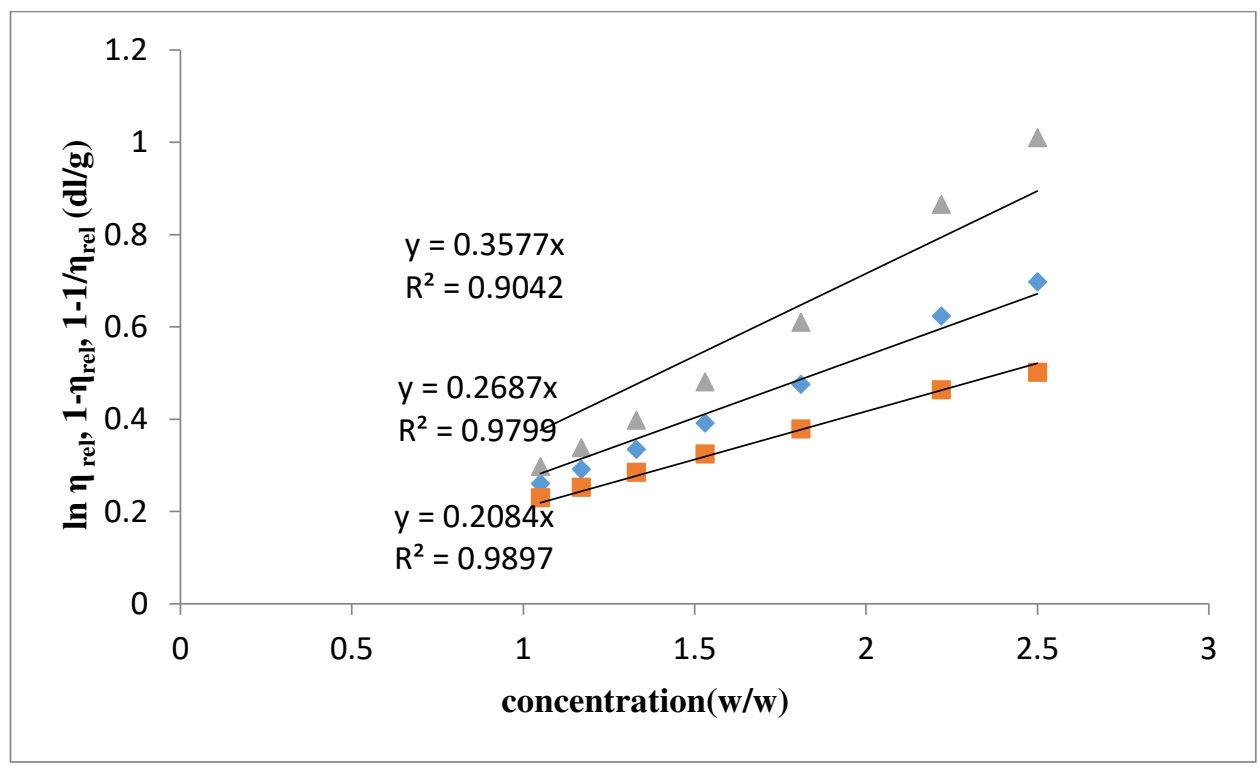

207 Figure 2. A typical triple Tanglertpaibul-Rao ( $\Delta)$, Higiro 1(») \& Higiro 2( $\bullet$ ) plots of Nettle seed gum (NSG) in deionized water $\left(25^{\circ} \mathrm{C}\right)$. 
210 Voluminosity and shape factor. The intrinsic viscosity depends on two critical molecular 211 parameters, namely the shape factor $(u)$ and voluminosity $\left(v_{s}\right)$. The shape factor is a 212 dimensionless parameter, which indicates the shape of a polymer in solution ${ }^{41}$. If the amount of 213 the shape factor $(v)$ is equal to 2.5 , the macromolecule shape is spherical, higher amount is 214 relevant to the ellipsoidal shape and amounts less than 2.5 show oblate or prolate shapes ${ }^{23}$. As 215 observed in Table 3, at the temperatures below $40{ }^{\circ} \mathrm{C}$, the shape factor value was less than 2.5 , 216 indicating that the NSG macromolecules are oblate/prolate in shape. At $40^{\circ} \mathrm{C}$, the shape factor 217 was 2.5, so the NSG polymers are spherical in shape. With increasing the temperature from $40^{\circ} \mathrm{C}$ 218 to $70^{\circ} \mathrm{C}$, the shape factor value of NSG increased from 2.55 to 7.24 , which represents more 219 expanded conformation (ellipsoidal) at high temperature (Table 3). These findings were 220 consistent with the data of intrinsic viscosity (Table 2). Regarding the impact of temperature on 221 the shape factor value, similar findings were reported by Yousefi et al. ${ }^{12}$, and Razavi et al. ${ }^{11}$. 222 Shape factor values of smaller than 2.5 were reported for cress seed gum and dextran gum by 223 Mohammad Amini et al. ${ }^{10}$, and Antonio et al. ${ }^{23}$, respectively.

224

\begin{tabular}{lll}
\hline \hline Temperature $\left({ }^{\circ} \mathrm{C}\right)$ & $v_{s}(\mathrm{dl} / \mathrm{g})$ & $v$ \\
\hline \hline 10 & $0.092 \pm 0.019^{\mathrm{a}}$ & $2.310 \pm 0.418^{\mathrm{c}}$ \\
25 & $0.089 \pm 0.001^{\mathrm{a}}$ & $2.330 \pm 0.019^{\mathrm{c}}$ \\
40 & $0.076 \pm 0.001^{\mathrm{a}}$ & $2.550 \pm 0.025^{\mathrm{c}}$ \\
55 & $0.036 \pm 0.002^{\mathrm{b}}$ & $4.380 \pm 0.272^{\mathrm{b}}$ \\
70 & $0.021 \pm 0.004^{\mathrm{b}}$ & $7.240 \pm 1.119^{\mathrm{a}}$ \\
\hline \hline
\end{tabular}


226 Table 3. Voluminosity $\left(v_{s}\right)$ and shape factor $(v)$ of Nettle seed gum (NSG) at different

227 temperatures. Results are expressed as means \pm SD for three replications. a-c: Means followed 228 by the same letters in the same column for each temperature are not significantly different $(\mathrm{P}>$ $2290.05)$.

231 The voluminosity or the swollen specific volume $\left(v_{s}\right)$ represents the polymer configuration in 232 various solvent conditions ${ }^{11,23}$. Solvent bonding causes the anhydrous macromolecule to expand 233 when dissolved or dispersed in water so that $v_{s}$ can be supposed as a scale of solvent bonding 234 with macromolecule or the macromolecule volume in solution per unit mass of biopolymer 235 without water ${ }^{42}$. The values of voluminosity $\left(\mathrm{v}_{\mathrm{s}}\right)$ of NSG at different temperatures are shown in 236 Table 3. By elevating the temperature from $10^{\circ} \mathrm{C}$ to $70^{\circ} \mathrm{C}$, the swollen specific volume declined 237 that shows the NSG polymer dimensions or the solvent power decreased ${ }^{11}$. As voluminosity is 238 described as the volume of the hydrated biopolymer per unit mass of dry biopolymer, the 239 achieved results from $v_{s}$ validated the obtained findings of the intrinsic viscosity (Table 3). 240 Similar findings regarding the impact of temperature on $v_{s}$ were reported by Razavi et al. ${ }^{11}$.

242 The molecular conformation. The coil overlap parameters including the master curve slope 243 (MCS), critical concentration $\left(\mathrm{C}^{*}\right)$ and the berry number $(\mathrm{C}[\eta])$. The plot of $\log \left(\eta_{\mathrm{sp}}\right)$ versus $\log$ $244 \mathrm{C}[\eta]$, which is known as the "master curve", is applied to designate the coil overlap parameters 245 in the dilute regime ${ }^{43,44}$. The berry number is a dimensionless parameter representing the volume 246 taken up by the polymer molecules in solution ${ }^{43,44}$. The molecular entanglements occur when 247 Berry number $(\mathrm{C}[\eta])$ is higher than one ${ }^{45,46}$, so in semi-dilute solutions, the Berry number is in 248 the range of $1.0-10.0^{45}$. In the present research, this parameter calculated for NSG solution was 
249 in the range of $0.21-0.52$ at $25^{\circ} \mathrm{C}$, which indicates that no coil overlap and molecular 250 entanglements happened (Table 4).

251

\begin{tabular}{llll}
\hline Temperature $\left({ }^{\circ} \mathrm{C}\right)$ & MCS & $\mathrm{C}[\eta]$ & $B$ \\
\hline 10 & $0.76 \pm 0.00$ & $0.29-0.51$ & $1.42 \pm 0.40^{\mathrm{b}}$ \\
25 & $0.81 \pm 0.00$ & $0.21-0.52$ & $1.44 \pm 0.01^{\mathrm{b}}$ \\
40 & $1.12 \pm 0.00$ & $0.25-0.48$ & $1.56 \pm 0.01^{\mathrm{b}}$ \\
55 & $1.32 \pm 0.40$ & $0.21-0.39$ & $1.95 \pm 0.04^{\mathrm{a}}$ \\
70 & $1.40 \pm 0.00$ & $0.24-0.37$ & $2.21 \pm 0.07^{\mathrm{a}}$ \\
\hline
\end{tabular}

252

Table 4. The values of master curve slope (MCS), Berry number $(\mathrm{C}[\eta])$ and exponent $b$ (slope of $254 \log \eta_{\text {sp }}$ vs. $\log$ C) of Nettle seed gum (NSG) solution at different temperatures. Results are 255 expressed as means \pm SD for three replications. a-b: Means followed by the same letters in the 256 same column for each temperature are not significantly different $(\mathrm{P}>0.05)$.

258 In a dilute solution, the master curve slope (MCS) value is less than 1.4, whereas for semi dilute 259 regime, the MCS has been found in some cases close to 3.75, However, the published values of 260 the slopes may vary for random coil polymers in good solvent from 3.4 up to $5^{43}$. At the 261 temperature range of $10-70^{\circ} \mathrm{C}$, the master curve slop for the NSG solution was less than 1.4 , 262 indicating that it was within the dilute solution domain and that no molecular entanglements was 263 present (Table 4).

264 The parameter $b$, the slope of the power-law model (equation (10)), is displayed in Table 4. 265 Morris et al. ${ }^{44}$ reported that within the dilute domain, parameter $b$ values higher than the number 
266 one is relevant to random coil conformation. In contrast, fewer values are a demonstration of 267 rod-like conformation. The parameter $b$ values for NSG at selected temperatures were ranged 268 from 1.42 to 2.2 , confirming the random coil conformation of the NSG macromolecules. Similar 269 data were reported by Yousefi et al. ${ }^{12}$ for sage seed gum. They also found that by elevating the 270 temperature from 25 to $65^{\circ} \mathrm{C}$, the amount of parameter $b$ increases.

271

272 Chain flexibility parameter and activation energy. The reduction in the viscosity of the polymer 273 solution in the Newtonian domain with increasing the temperature generally follows the 274 Arrhenius law. If the intrinsic viscosity was used in place of the Newtonian viscosity, the slope 275 of the logarithmic plot of the intrinsic viscosity $(\ln [\eta])$ against the inverse of absolute 276 temperature $(1 / \mathrm{T})$ is applied as an indicator of macromolecular chain flexibility $\left(\mathrm{E}_{\mathrm{a}} / \mathrm{R}\right)^{47}$. Thus, 277 high $E_{a} / R$ value indicates low chain flexibility ${ }^{25}$. The chain flexibility parameter $\left(E_{a} / R\right)$ and 278 activation energy $\left(\mathrm{E}_{\mathrm{a}}\right)$ calculated for the NSG at the studied temperatures were $587.2 \mathrm{~K}$ and $2790.488 \times 10^{7} \mathrm{~J} / \mathrm{kgmol}$, respectively. The chain flexibility parameter of NSG was lower than the 280 value obtained for sage seed gum $(3046.45)^{12}$, Balangu seed gum $(1156.53)^{10}$, xanthan $(1100)^{48}$, 281 cellulose diacetate $(645)^{49}$, Qodumeh Shirazi seed gum $(618.54)^{15}$, but it was more than chitosan $282(488)^{50}$, indicating greater flexibility of the macromolecular chain of NSG in comparison to most 283 hydrocolloids. Also, the value for the activation energy ( $\left.E_{a}\right)$ of NSG was lower than sage seed 284 gum $\left(2.53 \times 10^{7} \mathrm{~J} / \mathrm{kgmol}\right)^{12}$, chitosan $\left(2.5 \times 10^{7} \mathrm{~J} / \mathrm{kgmol}\right)^{51}$, Balangu seed gum $\left(1.00 \times 10^{7}\right.$ $285 \mathrm{~J} / \mathrm{kgmol}^{10}$, and almost similar to Qodumeh Shirazi seed gum $\left(0.51 \times 10^{7} \mathrm{~J} / \mathrm{kgmol}\right)^{15}$. 
In this paper, the influence of temperature $(10,25,40,55$, and $70 \circ \mathrm{C})$ on some molecular parameters and intrinsic viscosity of NSG in the dilute regime has been examined. After fitting different models, the Higiro 2 model was selected as the best model to explain the behavior of the dilute solution of NSG. According to the results, with increasing the temperature, the amount of intrinsic viscosity, and voluminosity $\left(\mathrm{v}_{\mathrm{s}}\right)$ decreased. The results of the shape factor $(\mathrm{v})$ showed that at temperatures below $40^{\circ} \mathrm{C}$, the NSG macromolecules are oblate/prolate in shape but at $40^{\circ} \mathrm{C}$, they are spherical. With raising the temperature from $10^{\circ} \mathrm{C}$ to $70^{\circ} \mathrm{C}$, the shape of NSG changed to ellipsoidal, indicating more expanded conformation at that high temperatures. Berry number and master curve slope (MCS) revealed that NSG solution at all temperatures was within the range of dilution solution regime and that no molecular entanglements were present. The value of the $b$ parameter at different temperatures was acquired in the range of 1.4-2.2, which indicates the NSG conformation was the random coil. Based on the Arrhenius-type model parameters, which expresses the chain flexibility parameter of the macromolecules, it was shown that NSG has a relatively flexible chain.

\section{References}

1. Davis, P.H. Flora of Turkey. 7, 633 (Edinburgh, 1982). reproductive system of streptozotocin-diabetic rats. Am J Pharmacol Toxicol, 4, 22-28 (2009).

3. Kavalali, G., \& Tuncel, H. Anti-inflammatory activities of Urtica pilulifera. Int. J. Pharmacognosy, 35, 138-140 (1997).

4. Zamani, Z., Razavi, S. M. A., \& Amiri, M.S. Determination of physicomechanical properties of Nettle seed (Urtica pilulifera) and optimization of its mucilage extraction conditions using response surface methodology. Research and Innovation in Food Science and Technology, 9, 143-160 (2020).

5. Zamani, Z., \& Razavi, S. M. A. Physicochemical, rheological and functional properties of Nettle seed (Urtica pilulifera) gum. Food Hydrocolloids, 112, 106304 (2021). 
6. Pamies, R., Cifre, J. G. H., Martínez, M. D. C. L., \& de la Torre, J. G. Determination of intrinsic viscosities of macromolecules and nanoparticles. Comparison of single-point and dilution procedures. Colloid and Polymer Science, 286, 1223-1231 (2008).

7. Tanglertpaibul, T., \& Rao, M. A. Intrinsic viscosity of tomato serum as affected by methods of determination and methods of processing concentrates. J. Food Science, 52, 1642-1645 (1987).

8. van Aken, G. A. Polysaccharides in Food Emulsions. Food polysaccharides and their applications, 521 (2006).

9. Behrouzian, F., Razavi, S. M. A., \& Karazhiyan, H. Intrinsic viscosity of cress (Lepidium sativum) seed gum: Effect of salts and sugars. Food Hydrocolloids, 35, 100-105 (2014).

10. Mohammad Amini, A. M., \& Razavi, S. M. A. Dilute solution properties of Balangu (Lallemantia royleana) seed gum: Effect of temperature, salt, and sugar. Int. J. Biological Macromolecules, 51, 235-243 (2012).

11. Razavi, S. M. A., Moghaddam, T. M., Emadzadeh, B., \& Salehi, F. Dilute solution properties of wild sage (Salvia macrosiphon) seed gum. Food Hydrocolloids, 29, 205-210 (2012).

12. Yousefi, A. R., Razavi, S. M. A., \& Aghdam, S. K. Influence of temperature, mono-and divalent cations on dilute solution properties of sage seed gum. Int. J. Biological Macromolecules, 67, 246-253 (2014).

13. Karazhiyan, H. et al. Physicochemical aspects of hydrocolloid extract from the seeds of Lepidium sativum. Int. J. Food Science \& Technology, 46, 1066-1072 (2011).

14. Razavi, S. M. A., Cui, S. W., Guo, Q., \& Ding, H. Some physicochemical properties of sage (Salvia macrosiphon) seed gum. Food Hydrocolloids, 35, 453-462 (2014).

15. Hesarinejad, M. A., Razavi, S. M. A., \& Koocheki, A. Alyssum homolocarpum seed gum: Dilute solution and some physicochemical properties. Int. J. Biological Macromolecules, 81, 418-426 (2015).

16. Kutlu, G., Bozkurt, F., \& Tornuk, F. Extraction of a novel water-soluble gum from nettle (Urtica dioica) seeds: Optimization and characterization. Int. J. biological macromolecules, 162, 480-489 (2020).

17. Da Silva, J. A. L., \& Rao, M. A. Viscoelastic Properties of Food Hydrocolloid Dispersions en Rao MA. Steffe, JF. (Eds.) Viscoelastic Properties of Foods, 285-315 (1992).

18. Huggins, M. L. The viscosity of dilute solutions of long-chain molecules. IV. Dependence on concentration. J. the American Chemical Society, 64, 2716-2718 (1942).

19. Kraemer, E. O. Molecular weights of celluloses and cellulose derivates. Industrial \& Engineering Chemistry, 30, 1200-1203 (1938).

20. McMillan, D. E. A comparison of five methods for obtaining the intrinsic viscosity of bovine serum albumin. Biopolymers: Original Research on Biomolecules, 13, 1367-1376 (1974).

21. Nickerson, M. T., Paulson, A. T., \& Hallett, F. R. Dilute solution properties of $\kappa-$ carrageenan polysaccharides: effect of potassium and calcium ions on chain conformation. Carbohydrate polymers, 58, 25-33 (2004).

22. Higiro, J., Herald, T. J., \& Alavi, S. Rheological study of xanthan and locust bean gum interaction in dilute solution. Food Research Int, 39, 165-175 (2006). 
23. Antoniou, E., Themistou, E., Sarkar, B., Tsianou, M., \& Alexandridis, P. Structure and dynamics of dextran in binary mixtures of a good and a bad solvent. Colloid and Polymer Science. 288, 1301-1312 (2010).

24. Lai, L. S., Tung, J., \& Lin, P. S. Solution properties of Hsian-Tsao (Mesona procumbens Hemsl) leaf gum. Food Hydrocolloids, 14, 287-294 (2000).

25. Chen, R.H. \& Lin, W.C. Effect of shear rate, temperature, ionic strength and $\mathrm{pH}$ on the rheological properties of chitosan solution. J. Fisheries Society of Taiwan, 19, 299-309 (1992).

26. Qian, K. Y., Cui, S. W., Wu, Y., \& Goff, H. D. Flaxseed gum from flaxseed hulls: Extraction, fractionation, and characterization. Food Hydrocolloids, 28, 275-283 (2012).

27. Wang, Q., \& Cui, S. W. Understanding the conformation of polysaccharides. Food carbohydrates: Chemistry, physical properties, and applications, 219, (2005).

28. Launay, B. Flow properties of aqueous solutions and dispersions of polysaccharides. Functional properties of food macromolecules, 1-19 (1986).

29. Higiro, J., Herald, T. J., Alavi, S., \& Bean, S. Rheological study of xanthan and locust bean gum interaction in dilute solution: Effect of salt. Food Research Int, 40, 435-447 (2007).

30. Lapasin, R., \& Pricl, S. Rheology of polysaccharide systems. In Rheology of industrial polysaccharides: Theory and applications. Springer, Boston, MA. 250-494 (1995).

31. Mirabolhassani, S. E., Rafe, A., \& Razavi, S. M. A. The influence of temperature, sucrose and lactose on dilute solution properties of basil (Ocimumbasilicum) seed gum. Int. J. biological macromolecules, 93, 623-629 (2016).

32. Ma, X., \& Pawlik, M. Intrinsic viscosities and Huggins constants of guar gum in alkali metal chloride solutions. Carbohydrate Polymers, 70, 15-24 (2007).

33. Lai, L. S., \& Chiang, H. F. Rheology of decolorized Hsian-Tsao leaf gum in the dilute domain. Food hydrocolloids, 16, 427-440 (2002).

34. Stivala, S. S., \& Bahary, W. S. Some dilute-solution parameters of the levan of Streptococcus salivarius in various solvents. Carbohydrate Research, 67, 17-21 (1978).

35. Haug, A. R. N. E., \& Smidsrod, O. Determination of intrinsic viscosity of alginates. Acta Chem. Scand, 16, 1569-1578 (1962).

36. Milani, J., \& Maleki, G. Hydrocolloids in food industry. Food industrial processesMethods and equipment, 2, 2-37 (2012).

37. Pachuau, L., Lalhlenmawia, H., \& Mazumder, B. Characteristics and composition of Albizia procera (Roxb.) Benth gum. Industrial crops and products, 40, $90-95$ (2012).

38. Richardson, P. H., Willmer, J., \& Foster, T. J. Dilute solution properties of guar and locust bean gum in sucrose solutions. Food Hydrocolloids, 12, 339-348 (1998).

39. Rao, M.A. Rheology of fluid and semi-solid foods (Principles and Applications). Aspen publication (1999).

40. Lin, H. Y., \& Lai, L. S. Isolation and viscometric characterization of hydrocolloids from mulberry (Morus alba L.) leaves. Food hydrocolloids, 23, 840-848 (2009).

41. Joseph, R., Devi, S., \& Rakshit, A. K. Viscosity behaviour of acrylonitrile-acrylate copolymer solutions in dimethyl formamide. Polymer Int, 26, 89-92 (1991).

42. Harding, S. E. The intrinsic viscosity of biological macromolecules. Progress in measurement, interpretation and application to structure in dilute solution. Progress in Biophysics and Molecular Biology, 68, 207-262 (1997). 
43. Launay, B., Cuvelier, G., \& Martinez-Reyes, S. Viscosity of locust bean, guar and xanthan gum solutions in the Newtonian domain: a critical examination of the log ( $\eta \mathrm{sp})$ o- $\log \mathrm{C}[\eta]$ o master curves. Carbohydrate Polymers, 34, 385-395 (1997).

44. Morris, E. R., Cutler, A. N., Ross-Murphy, S. B., Rees, D. A., \& Price, J. Concentration and shear rate dependence of viscosity in random coil polysaccharide solutions. Carbohydrate polymers, 1, 5-21 (1981).

45. Graessley, W. W. The entanglement concept in polymer rheology. The entanglement concept in polymer rheology, Springer, Berlin, Heidelberg, 1-179 (1974).

46. Hager, B. L., \& Berry, G. C. Moderately concentrated solutions of polystyrene. I. Viscosity as a function of concentration, temperature, and molecular weight. J. Polymer Science: Polymer Physics Edition, 20, 911-928 (1982).

47. Rinaudo, M., \& Domard, A. Chitin and chitosan. Solution properties of chitosan. London, UK: Elsevier, 71-86 (1989).

48. Milas, M., \& Rinaudo, M. Properties of xanthan gum in aqueous solutions: role of the conformational transition. Carbohydrate Research, 158, 191-204 (1986).

49. Kamide, K., \& Saito, M. Cellulose and cellulose derivatives: Recent advances in physical chemistry. Int. Biopolymers. Springer, Berlin, Heidelberg. 1-56 (1987).

50. Pogodina, N. et al. Conformational characteristics of chitosan molecules as demonstrated by diffusion-sedimentation analysis and viscometry. Polymer Science USSR, 28, 251-259 (1986).

51. Wang, W., \& Xu, D. Viscosity and flow properties of concentrated solutions of chitosan with different degrees of deacetylation. Int. J. Biological Macromolecules, 16, 149-152 (1994).

\section{Acknowledgements}

This project was funded by the Iran National Science Foundation (INSF), Iran (Grant No., 96015540) and the Deputy of Research, Ferdowsi University of Mashhad, Iran (Grant No. 49170). The financial supports are gratefully acknowledged.

\section{Author contributions}

Z.Z. done the experiments, analyzed and interpenetrated the data, prepared the manuscript and revised the paper. S.M.A.R. designed the research, provided the fund and laboratory facilities, checked the data, controlled the analysis, edited the paper, revised the paper and submitted the paper. 
440 Competing interests

441 The authors declare no competing interests.

442

443 Additional information

444 Correspondence and requests for materials should be addressed to S.M.A.R.

445

446 
Figures

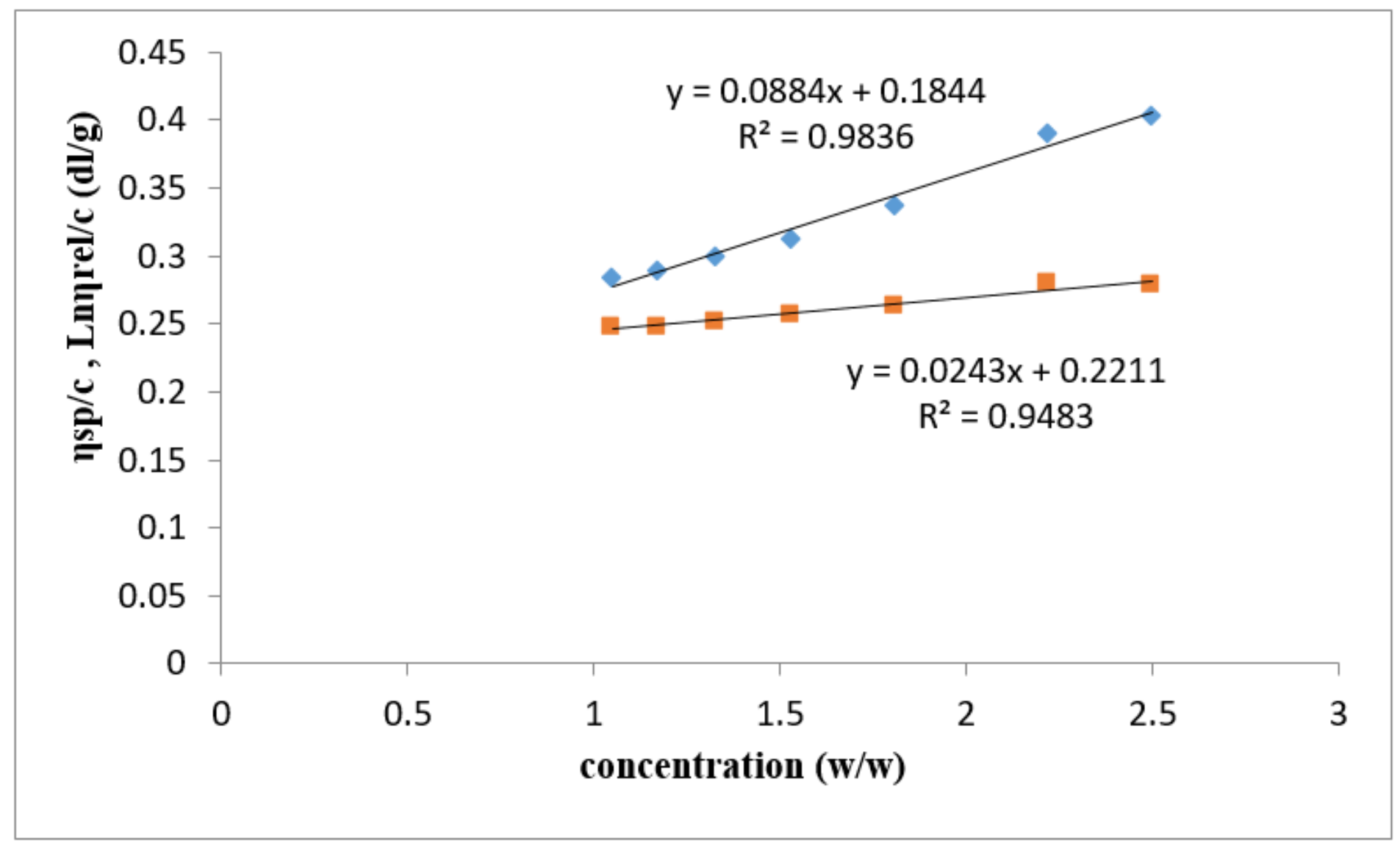

Figure 1

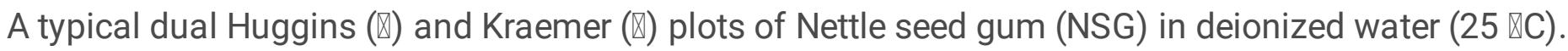




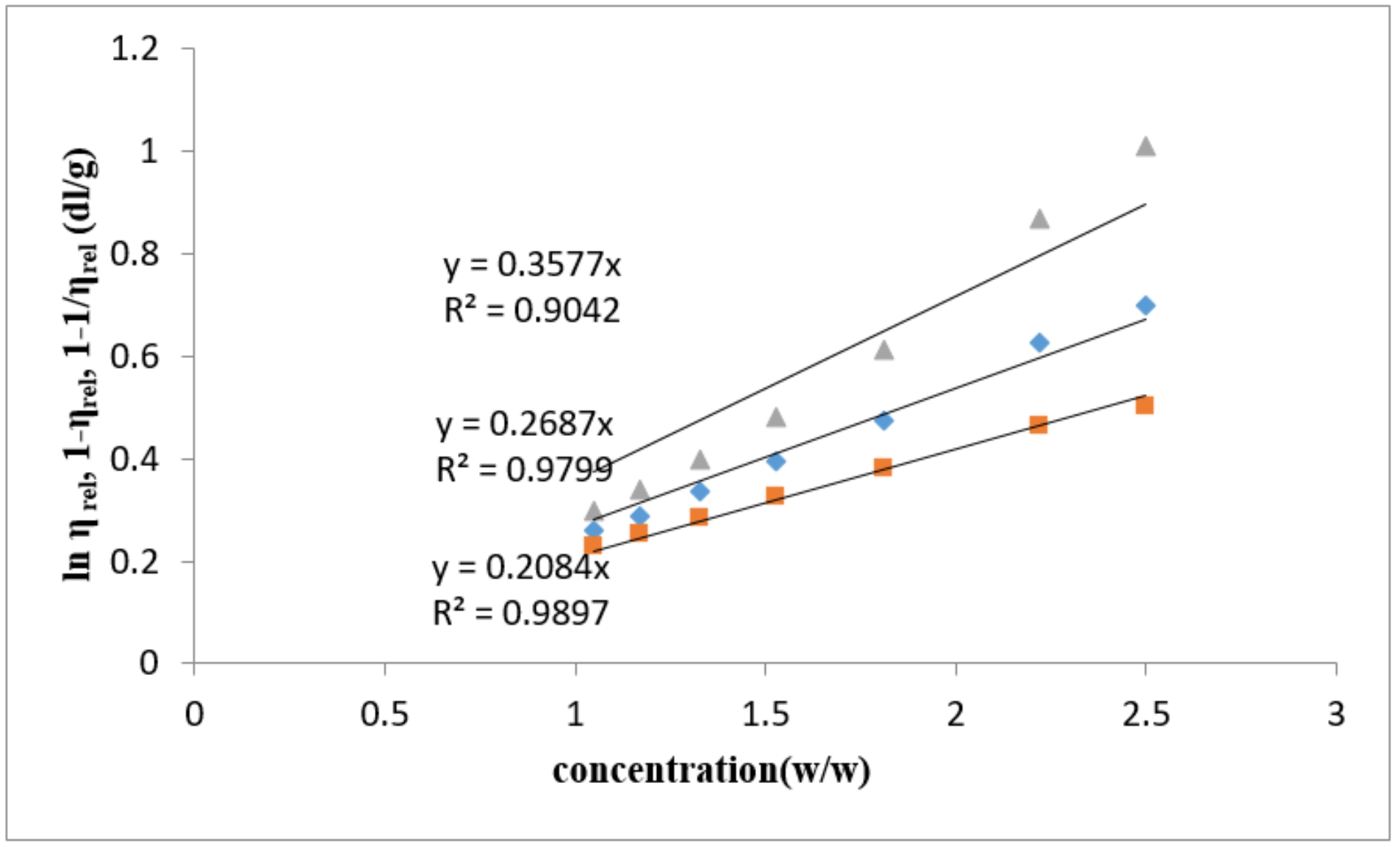

Figure 2

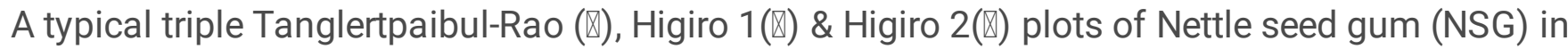
deionized water $(25 \llbracket C)$. 